\title{
Third degree perineal lacerations-How, why and when? A review analysis
}

\author{
Angelos Daniilidis ${ }^{1}$, Vasilis Markis ${ }^{1}$, Menelaos Tzafetas ${ }^{1}$, Panagiotis Loufopoulos ${ }^{1}$, Panagiotis Hatzis ${ }^{1}$, \\ Nikolaos Vrachnis ${ }^{2}$, Konstantinos Dinas ${ }^{1}$ \\ ${ }^{1}$ Department of Obstetrics and Gynecology, Hippokratio General Hospital, Aristotle University of Thessaloniki, Thessaloniki, Greece \\ ${ }^{2}$ Department of Obstetrics and Gynaecology, Ateraieio Hospital, Athens, Greece \\ Email: menelaos.tzafettas@gmail.com
}

Received 28 March 2012; revised 30 April 2012; accepted 13 May 2012

\begin{abstract}
Aim: The aim of this article is to present the knowledge of current literature regarding epidemiology and predisposing factors, classification and surgical treatment of third degree perineal tears. Materials and Methods: We reviewed current articles in English language from medline and Pub-Med using as key words "vaginal repair, third degree tear, episiotomy and vaginal delivery". We summarized literature regarding predisposing factors, epidemiology, prevention and surgical treatment of third degree perineal tears. Results: it is demonstrated today by several studies that widespread episiotomy is responsible for the increasing frequency of 3rd degree lacerations of the perineum which are significantly associated with forceps and the use of gynecological chair (boom) for vaginal delivery. Primiparous women with babies weighting $>4 \mathrm{kgr}$, are at greater risk. Two types of surgical repair: end-to-end approximation and overlapping of torn ends of the anal sphincter, are both related to the functional outcome of the repair. Conclusion: Episiotomy is an important risk factor for severe lacerations after vaginal delivery. Midline episiotomy and assisted vaginal delivery should be avoided whenever possible, especially in the presence of a large baby. Recent evidence suggests that there is no significant advantage between overlap repair and approximation technique, with regard to fecal incontinence.
\end{abstract}

Keywords: Vaginal Repair; Third Degree Tear; Episiotomy; Vaginal Delivery

\section{INTRODUCTION}

Third degree perineal lacerations are known since the time of Hippocrates. They involve a tear in the vagina, skin, muscles between the vagina and anus (perineal skin
\& perineal muscles) and anal sphincter. Directly underneath the layer of squamous epithelium and vaginal mucosa lies the perineal body which is triangular in shape and is the join connection between bulbospongiosus, superficial transverse perineal and anal sphincter muscles. The anal sphincter consists of two separate muscles: the internal and the external anal sphincter. A tear can be through one or both of these muscles (Figure 1).

The classification system establishes a framework for evaluation, discussion of the degree of injury, appropriate treatment and rehabilitation research. In the USA, a classification system of four levels is used, in contract to a three level system used in Europe (Europe's third level corresponds to the fourth level of America) (Table 1).

Perineal tears occur more frequently in the presence of median episiotomy or in operative vaginal deliveries. In developed countries the incidence of third-degree perineal tears ranges between $0.5 \%$ and $1 \%$ of all vaginal deliveries [1]. Proper assessment and rehabilitation is necessary to prevent complications. The degree of laceration is

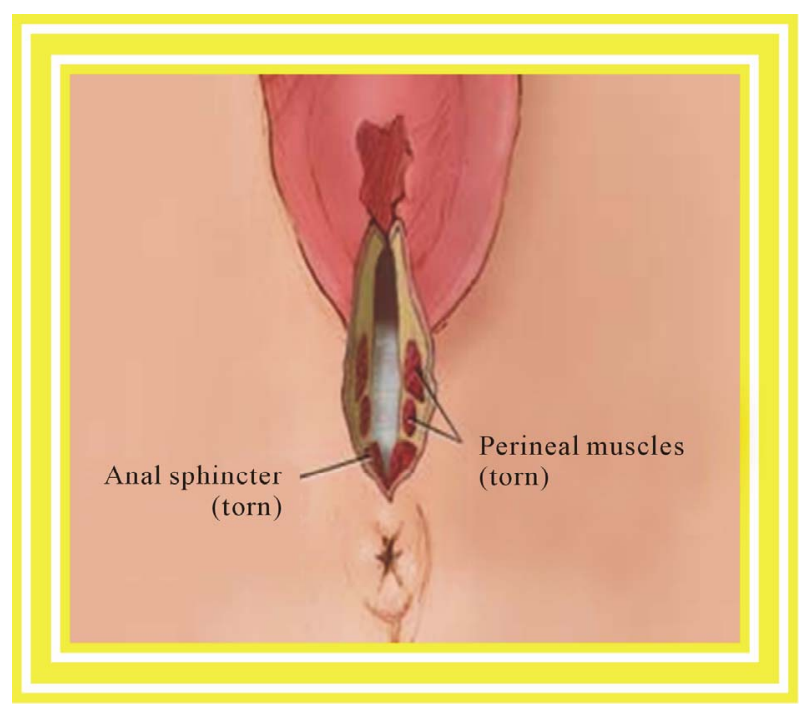

Figure 1. Third degree laceration. 
Table 1. Classification of perineal tears.

\begin{tabular}{cc}
\hline & Degree of laceration \\
\hline $\begin{array}{c}\text { First degree } \\
\text { Second degree }\end{array}$ & Superficial laceration of the vaginal mucosa or perineal body. \\
Third degree incomplete & Laceration of the vaginal mucosa and/or perineal skin and deeper subcutaneous tissues. \\
Third degree complete & Second degree laceration with laceration of the capsule and part (but not all) of the anal sphincter muscle. \\
Fourth degree & As above with complete laceration of the anal sphincter muscle. \\
Complete third degree laceration with laceration of the rectal mucosa.
\end{tabular}

graded and determines the method of repair, the technique of which has changed little over the past 50 years. Episiotomy is the overriding determinant of third-degree lacerations [2].

The aim of this article is to review the current literature regarding epidemiology, predisposing factors, classification and surgical treatment of third degree perineal tears.

\subsection{Predisposing \\ Factors-Epidemiology-Prevention}

The first proposal for episiotomy was made by Ould in 1742 to facilitate the $2^{\text {nd }}$ stage of labour. It was not until 1920 when Delle and Pomeroy published several articles suggesting that the wide use of routine episiotomy to primiparous women, provide protection from the $3^{\text {rd }}$ degree perineal lacerations. In 1948 the Kaltreider and Dixon [3] noted the high incidence of rectal lacerations with median episiotomy and created the question of the effectiveness in practice [3]. The widespread episiotomy today is demonstrated through studies to be responsible for the increasing frequency of $3^{\text {rd }}$ degree lacerations. The medio-lateral episiotomy seems to have an advantage in comparison to median episiotomy. The trend is that it should be used only when necessary [1,3-5]. A conservative approach to the use of mediolateral episiotomy consists a reasonable solution in order to prevent third-degree lacerations [6]. Reduction in episiotomy results in less posterior perineal trauma, less aggregation and fewer complications, but there is no difference in the degree of pain and severe vaginal and perineal trauma. On the contrary there seems to be an increased risk of anterior wall trauma.

The use of gynecological chair (boom) for vaginal delivery, increases the risk of third degree perineal tears.

In cases of spontaneous births the use of episiotomy is limited to 1 in 5 spontaneous deliveries There is a significant association between third degree perineal lacerations and the use of forceps [1,6]. Evidence shows that in operative delivery methods, vacuum extractor has an advantage over the use of metallic forceps regarding the risk for third degree tears. The same applies for the prevention of faecal incontinence $[7,8]$. Following this com- plication about $44 \%$ of the patients remain symptomatic [8].

Third-degree tears are significantly more common in primigravidae and mothers with high birth-weight babies [9]. Primiparous women who have delivered babies with weight $>4 \mathrm{kgr}$, have a greater risk for third degree perineal lacerations. There are also reports and studies according to which multiparous women following operative delivery and episiotomy are at increased risk compared to women who deliver spontaneously (Table 2).

Gestational age, marital status, weight before pregnancy, weight gain during pregnancy, height, education, labour or physical condition are factors which don't seem to be associated with this type of injuries. Factors that could increase perineal integrity are: spontaneous or vacuum assisted delivery, rather than forceps, also avoiding episiotomy, allowing time for perineal thinning and perineal massage during the weeks before childbirth in nulliparous women.

Before treatment we have to focus on contradictory preventive strategies. It might seem that restrictive episiotomy has been shown to result in less posterior perineal trauma, less suturing and fewer complications, but there is no difference for severe vaginal or anterior wall trauma $[1,3,5]$.

\subsection{Surgical Techniques for Repairing Third Degree Perineal Tear}

A cooperative patient is of very high importance for good exposure and adequate repair. Anesthesia should be always used and epidural anesthesia is considered to be the

Table 2. Risk factors associated with third-degree perineal tears [1].

\begin{tabular}{l}
\hline Routine episiotomy (midline > mediolateral) \\
Delivery with stirrups (delivery table, lithotomy) \\
Operative delivery (metal forceps > vacuum extractor) \\
Experience of delivering provider \\
Prolonged second stage of labor \\
Nulliparity \\
Occipital posterior or occipital transverse position \\
Anesthesia (local or epidural) \\
Age of pregnant women (less than 21 years) \\
Use of oxytocin \\
\hline
\end{tabular}


gold standard type. When regional anaesthesia, epidural or spinal are not available, an adequate pudendal block and inhalation anaesthetic or general anesthesia remain the option. Ten milliliters of a local anesthetic (lidocaine, chloroprocaine, bupivacaine) should be injected below the ischial spines bilaterally and at least ten more to the laceration area. Enough care should be taken to make sure that the rectal sphincter is anesthetized prior to the repair.

It is essential that the full extent of the laceration is discerned, including extension of the laceration and "button holes" defecting into the rectal mucosa. A careful rectal examination should be performed with the use of index finger by elevating the anterior rectal wall into the vagina. The rectal glove should be changed before continuing with the repair. It is often useful to place a pad (usually a long pack of gauze pad) high into the vagina to prevent blood from the uterus of obscuring the view. Sometimes the anatomy is not clear and it becomes more apparent as the wound is being repaired. If the tear is complex, a more experienced operator may be required.

In order to decrease dead space and strengthen the rectovaginal septum, three to four interrupted or running 00-polyglycolic acid sutures should be placed into the internal anal sphincter and rectovaginal fascia. Of course care should be taken to prevent entry into the rectal lumen $[1,10]$.

Where the internal anal sphincter can be identified, it is advisable to be repaired separately with interrupted sutures. The size of suture must be such as 3-0 PDS and 2-0 Vicryl which may cause less irritation and discomfort [11].

Regarding repair of the external anal sphincter there are two surgical techniques, the overlapping and the end to end (approximation) method. The ends of the sphincter must be clearly identified and grasped with Alis clamps.

The end-to-end technique is used to bring the ends of the sphincter together at each quadrant $(12,3,6$, and 9 o'clock) using interrupted sutures placed through the capsule and muscle (Figure 2) [12,13].

Allis Clamps are placed on each end of the external anal sphincter. Monofilament sutures such as polydiaxanone (PDS) or modern braided interrupted sutures such as polyglactin (Vicryl) are placed at "posterior, inferior, superior and anterior" side of sphincter. Recent evidence suggests that end-to-end repairs have poorer anatomic and functional outcomes than was previously believed $[1,14]$.

An alternative technique is overlapping repair of the external anal sphincter. It brings together the ends of the sphincter with mattress sutures (Figure 2) and results in a larger surface area of tissue contact between the two torn ends. Dissection of the external anal sphincter from

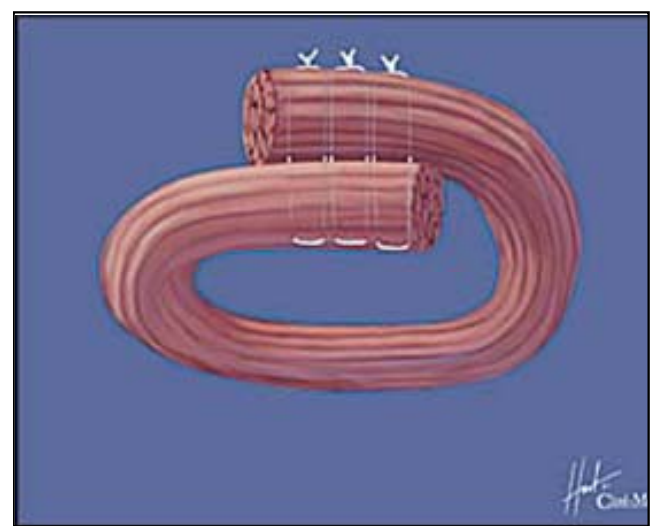

(a)

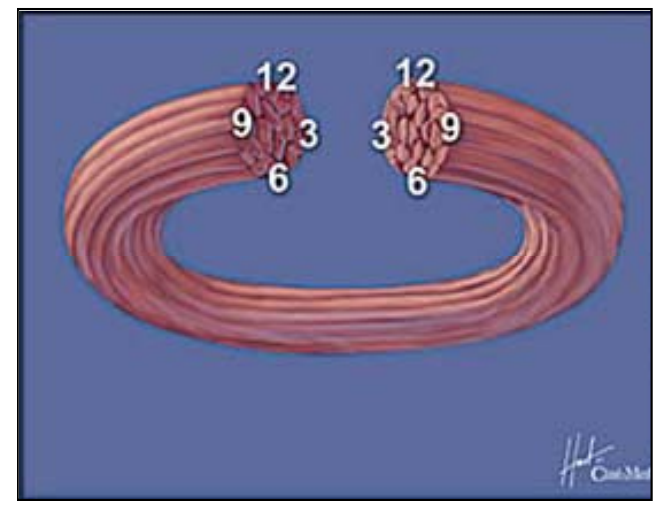

(b)

Figure 2. Over lap (a) and end to end technique (b).

the surrounding tissue with Metzenbaum scissors may be required to achieve adequate length for the overlapping of the muscles. The suture is passed from top to bottom through the superior and inferior flaps, then from bottom to top through the inferior and superior flaps. The proximal end of the superior flap overlies the distal portion of the inferior flap. Two more sutures are placed in the same manner. After all three sutures are placed, they are each tied snugly, but without strangulation. When tied, the knots are on the top of the overlapped sphincter ends. Care must be taken to incorporate the muscle capsule in the closure [15-17].

A recent randomized controlled study of one hundred and twenty-eight patients with grade three tears, included 119 (end-to-end 60, overlap 59) which received the allocated treatment. The obtained information concerning fecal incontinence from 101 (85\%) patients shows that one patient in the end-to-end group and none in the overlap group reported leakage of solid stool once a week or more. Fourteen patients in the end-to-end group and 10 in the overlap group reported flatus incontinence $(\mathrm{p}=0.48)$. Defect of external sphincter was found in $2 / 46$ in the end-to-end group compared to $0 / 41$ in the overlap group (NS). There was no difference in anal manometry findings in both groups. Compendiously 
there was no significant advantage between overlap repair and approximation technique with regard to fecal incontinence at 1 year [18].

Current RCOG (Royal College of Obstetricians and Gynecologists) classification of obstetrics perineal trauma pintpoints that the anatomic structures together with the physiological functions of tissue involved in ano-rectal continence should always be respected [11]. Experience of the surgeon, operating theatre and its equipment, asepsis, lighting, operating instruments, anesthesia, material and type of suture as well as medication, are related with the effectiveness of the repair. A delay up to 8 - 12 hours in primary repair does not seem to be detrimental to the functional outcome of the procedure [19].

\subsection{Complications of Third Degree Tears and Treatment Methods}

Several studies give an estimation of $15 \%$ of complications of third degree laceration repairs. The most common complications are: wound dehiscence, hematoma, rectovaginal fistula, rectocutaneus fistula, perineal abscess, anal incontinence, dyspareunia. The most common etiologies for these kinds of complications are summarized in Table 3. These complications occur in patients with insulin-dependent diabetes, cancer, or an immunosuppressive disorder. Multiple bacterial pathogens are responsible for necrotizing fasciitis and the wound should be recognized of the cyanotic discoloration and the loss of sensation. This situations should be usually managed with surgical debridement and allowance of broad spectrum antibiotics $[1,16,20]$. In a retrospective study of 27 women with 140 days follow up the feasibility of an overlapping anal sphincter repair instead of end to end repair was evaluated [21]. The study includes women who delivered vaginally between June 1995-November 1996 complicated by a third degree perineal tear (Table 4). The internal sphincter was repaired separately and the torn ends of the external sphincter were overlapped and sutured with 3/0 PDS sutures (Ethicon, Edinburgh, UK).

Table 3. Etiology of complications.

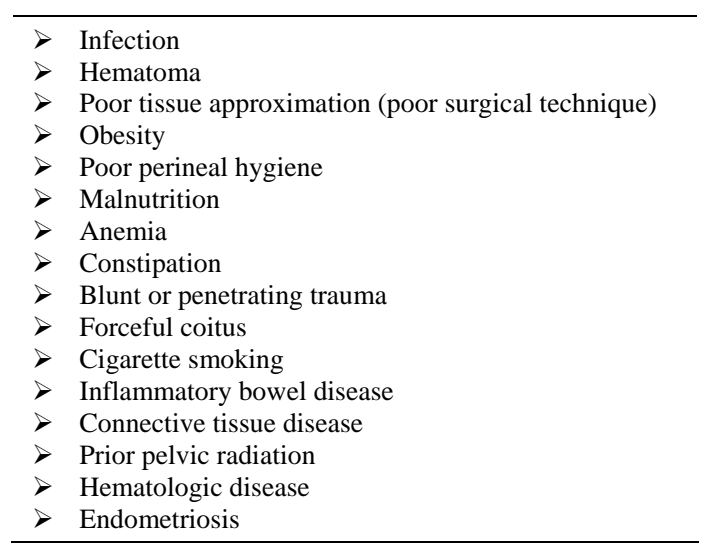

Table 4. Bowel symptoms, anal manometry and endosonography in women with overlap sphincter repair $(n=27)$. Values are given as $n(\%)$ [21].

\begin{tabular}{cc}
\hline Symptoms & Percent \\
\hline Incontinence of flatus & $8 \%$ \\
Anal endosonography & \\
External sphincter & $15 \%$ \\
Internal sphincter & $44 \%$ \\
Bowel symptoms & \\
Faecal urgency & $15 \%$ \\
\hline
\end{tabular}

The conclusion of this study was that there are reservations regarding the feasibility of the overlap versus end to end repair technique. Another retrospective cohort study included 626 primiparous women with three and six months follow up, after vaginal delivery [22]. 209 of them received an episiotomy, 206 did not but experienced a second, third, or fourth degree spontaneous perineal laceration and 211 had no laceration or a first degree perineal laceration. This study concluded that midline episiotomy is not effective in protecting the perineum and sphincters during childbirth and may impair anal continence (Table 5). A new study [23] was performed to evaluate the prevalence of anal incontinence (AI) in primiparous women five years after their first delivery. It included 242 primiparous women in order to evaluate the prevalence of anal incontinence (AI) in five years after their first delivery. Women with sphincter tear $(\mathrm{n}=36)$ at their first delivery were compared to women without such injury $(\mathrm{n}=206)$. Anal incontinence increased significantly after the 5-year follow-up. Among women with sphincter tears, $44 \%$ reported anal incontinence at nine months and $53 \%$ at five years $(p=0.002)$. Risk factors for anal incontinence at five years were age (OR 2.2, 95\% CI 1.0; 4.6), sphincter tear (OR 2.3, 1.1; 5.0) and subsequent childbirth (OR 2.4, 1.1; 5.6) (Table 6). In this cohort study thirty-six (15\%) of the women had a sphincter tear. After 9 months, 68/242 women (28\%) reported anal incontinence symptoms and after 5 years 85/242 women (35\%) reported symptoms of anal incontinence ( $<<0.0001)$ (Table 7, Figure 3). Another systematic review on the method of repair of third-degree tears [24] included three trials of 279 women. This review reported that there was no significant difference in perineal pain (RR0.08, 95\% CI 0.00 - 1.45), dyspareunia (RR 0.62, 95\% CI 0.11 - 3.39), flatus incontinence (RR $0.93,95 \%$ CI 0.2 - 3.31) and faecal incontinence (RR 0.07, 95\% CI 0.00 - 1.21), between the two repair techniques at 1 year, but there was a significantly lower incidence in faecal urgency (RR 0.12, 95\% CI 0.02 0.86). Some studies report anal incontinence symptoms 
Table 5. Risk of anal incontinence three and six months after childbirth for varying degrees of perineal injury. Figures are numbers (percentage) of women [22].

\begin{tabular}{ccccccc}
\hline Outcome & $\begin{array}{c}\text { Intact/1st degree tear } \\
\text { (intact group) }\end{array}$ & $\begin{array}{c}\text { 2nd } \\
\text { degree tear }\end{array}$ & $\begin{array}{c}\text { 3rd/4th } \\
\text { degree tear }\end{array}$ & $\begin{array}{c}\text { 2nd/3rd/4th degree } \\
\text { tear (tear group) }\end{array}$ & $\begin{array}{c}\text { Episiotomy } \\
\text { (episiotomy group) }\end{array}$ & $\begin{array}{c}\text { Episiotomy with } \\
\text { no extension }\end{array}$ \\
\hline Faecal incontinence & & & & & & \\
At 3 months & $5 / 205(2.4)$ & $5 / 154(3.3)$ & $2 / 50(4.0)$ & $7 / 204(3.4)$ & $20 / 203(9.9)$ & $13 / 147(8.8)$ \\
At 6 months & $3 / 201(1.5)$ & $3 / 152(2.0)$ & $0 / 49(0)$ & $3 / 201(1.5)$ & $8 / 195(4.1)$ & $6 / 141(4.3)$ \\
Flatus incontinence: & & & & & & \\
At 3 months & $40 / 192(20.8)$ & $27 / 144(18.8)$ & $9 / 48(18.8)$ & $36 / 192(18.8)$ & $63 / 187(33.7)$ & $39 / 137(28.5)$ \\
At 6 months & $20 / 188(10.6)$ & $18 / 142(12.7)$ & $5 / 47(10.6)$ & $23 / 189(12.2)$ & $42 / 181(23.2)$ & $26 / 133(19.6)$ \\
\hline
\end{tabular}

Table 6. Type of delivery and sphincter tear [23].

\begin{tabular}{ccc}
\hline Number and type of delivery & No sphincter tear $(\mathbf{n}=\mathbf{2 0 6})$ & Sphincter tear $(\mathbf{n}=\mathbf{3 6})$ \\
\hline No subsequent childbirth & 44 & 9 \\
One subsequent vaginal delivery & 134 & 20 \\
Two subsequent vaginal deliveries & 20 & 3 \\
Three subsequent vaginal deliveries & 1 & 0 \\
One subsequent c-section & $8^{*}$ & 3 \\
Two subsequent c-sections & 0 & 3 \\
\hline
\end{tabular}

*One woman had both a c-section and a vaginal delivery.

Table 7. Degree of fecal incontinence and involuntary flatus [23].

\begin{tabular}{|c|c|c|c|c|}
\hline \multicolumn{2}{|l|}{ Symptoms } & \multicolumn{2}{|l|}{ Sphincter tear } & \multirow{2}{*}{$\begin{array}{l}\text { No sphincter tear } \\
5 \text { yrs after delivery }\end{array}$} \\
\hline 9 mo after delivery & \multicolumn{2}{|c|}{5 yrs after delivery } & 9 mo after delivery & \\
\hline No incontinence & $56 \%(20 / 36)$ & $47 \%(17 / 36)$ & 75\% (154/206) & $68 \%(140 / 206)$ \\
\hline \multicolumn{5}{|c|}{ Fecal incontinence } \\
\hline$<1 /$ week & 0 & $11 \%(4 / 36)^{* *}$ & $1 \%(3 / 206)^{*}$ & $4 \%(9 / 206)^{* * *}$ \\
\hline$>1 /$ week & 0 & 0 & 0 & $0.5 \%(1 / 206)^{* * * * *}$ \\
\hline Daily & 0 & 0 & 0 & 0 \\
\hline \multicolumn{5}{|c|}{ Involuntary flatus } \\
\hline$<1 /$ week & $33 \%(12 / 36)$ & $25 \%(9 / 36)$ & $16 \%(33 / 206)$ & $22 \%(45 / 206)$ \\
\hline$>1 /$ week & $11 \%(4 / 36)$ & $22 \%(8 / 36)$ & $7 \%(14 / 206)$ & $7 \%(15 / 206)$ \\
\hline Daily & 0 & $6 \%(2 / 36)$ & $1 \%(3 / 206)$ & $2 \%(5 / 206)$ \\
\hline
\end{tabular}

* One woman also had incontinence to flatus; ${ }^{* *}$ All women were also incontinent to flatus; ${ }^{* * *}$ All but one woman were also incontinent to flatus; ${ }^{* * * *}$ The women also were incontinent to flatus.

in $20 \%-67 \%$ of women with primary third-degree tear repair. The type of incontinence is mainly flatus (up to $59 \%$ ) with leakage of liquid and solid stool in up to $11 \%$, while faecal urgency occurred in $26 \%$ of these women. In one study, there were symptoms of anal incontinence after four years of follow-up (17\% - 42\%) [11,25]. These studies used different questionnaires to assess anal incontinence symptoms and it is not easy to compare studies' outcomes [11]. Several randomised controlled studies since 2000 comparing overlap and end-to-end techniques of EAS repair, report low incidences of anal incontinence symptoms in both sides, describing as asymptomatic $60 \%-80 \%$ of women at 1 year 11 . A randomized controlled trial study investigates the association between endoanal ultrasonography and anorectal manometry in relation to anal incontinence after primary repair of ob 


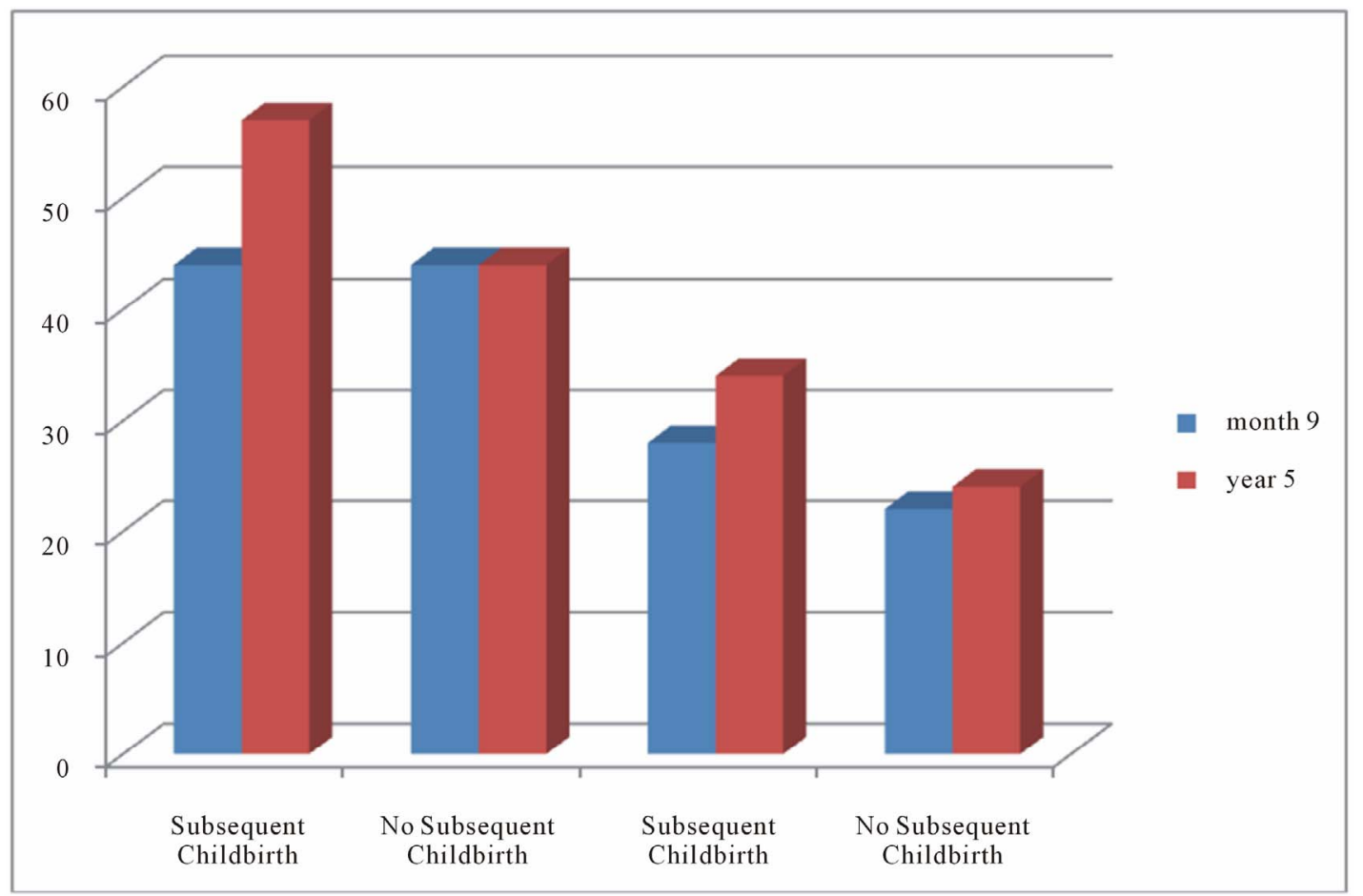

Figure 3. Anal incontinence at 9 months and 5 years in relation to subsequent childbirth [26]. Sphincter refers to tear or no tear at the index delivery.

stetric sphincter injury in primiparous, premenopausal women. It included 108 women who had previously been part of a delayed primary repair of obstetric sphincter injuries, and 12 months after the repair, they had been evaluated by anorectal manometry and endoanal ultrasound. Impaired rectal sensation at anorectal manometry and a scar at endoanal ultrasonography are associated with anal incontinence 12 months after primary sphincter repair in primiparous women [26].

Studies using endoanal ultrasound as follow-up show persistent defects in $54 \%$ - $88 \%$ of women after primary repair of third-degree tears. More recently, randomised controlled trials have reported fewer residual defects (about 19\% - 36\% overall). The clinical relevance of asymptomatic defects demonstrated by ultrasound is currently unclear $[11,26]$.

\section{CONCLUSION}

Although episiotomy is an important risk factor for severe lacerations after vaginal delivery, there are other significant independent risk factors, such as maternal age, birth weight, and assisted vaginal delivery, which should be considered in counseling and making decisions regarding delivery modality. Older patients who deliver their first child are at higher risk for severe laceration. Midline episiotomy and assisted vaginal delivery should be avoided in this population whenever possible, especially in the presence of a large baby. Recent evidence suggests that no significant advantage between overlap repair and approximation technique exists with regard to fecal incontinence.

\section{REFERENCES}

[1] Atwood, L., Deutchman, C.M., Bailey, E., Quinlan, J. and Abercrombie, S. (2003) Advanced life support in obstetrics advisory board, 2003-2004. 4th Edition, 1-13.

[2] Nager, C.W. and Helliwell, J.P. (2001) Episiotomy increases perineal laceration length in primiparous women. American Journal of Obstetrics \& Gynecology, 185, 444450. doi:10.1067/mob.2001.116095

[3] Michel Labrecque, M.D., et al. (1997) Association between median episiotomy and severe perineal lacerations in primiparous women. Canadian Medical Association, 156, 797-802.

[4] Helwig, J.T., et al. (1993) Does midline episiotomy increase the risk of the third- and fourth-degree lacerations in operative vaginal deliveries? Obstetrics \& Gynecology, 82, 276-279.

[5] Bodner-Adler, B., Bodner, K., Kaider, A., Wagenbichler, P., Leodolter, S., Husslein, P. and Mayerhofer, K. (2001) Risk factors for third-degree perineal tears in vaginal delivery, with an analysis of episiotomy types. The Journal of Reproductive Medicine, 46, 752-756.

[6] Henriksen, T.B., Bek, K.M., Hedegaard, M. and Secher, N.J. (1992) Episiotomy and perineal lesions in spontaneous vaginal deliveries. British Journal of Obstetrics and Gynaecology, 99, 950-954. 


\section{doi:10.1111/j.1471-0528.1992.tb13695.x}

[7] De Leew, J.W., Struijk, P.C., Vierhout, M.E. and Wallenburg, H.C. (2001) Risk factors for third degree perineal ruptures during delivery. British Journal of Obstetrics and Gynaecology, 108, 383-387. doi:10.1016/S0306-5456(00)00090-5

[8] Williams, A. (2003) Third-degree perineal tears: Risk factors and outcomes after primary repair. American Journal of Obstetrics \& Gynecology, 23, 611-614. doi:10.1080/01443610310001604358

[9] Bodner, K., Bodner-Adler, B., Wagenbichler, P., Kaider, A., Leodolter, S., Husslein, P. and Mayerhofer, K. (2001) Perineal lacerations during spontaneous vaginal delivery. Wiener Klinische Wochenschrift, 113, 743-746.

[10] Peleg, D., Kennedy, C.M., Merrill, D. and Zlatnik, F.J. (1999) Risk of repetition of a severe perineal laceration. Obstetrics \& Gynecology, 93, 1021-1024. doi:10.1016/S0029-7844(98)00556-0

[11] Royal College of Obstetricians and Gynecologists (2007) The management of third- and fourth-degree perineal tears. Green-Top Guideline.

[12] Sultan, A.H., Kamm, M.A., Hudson, C.N. and Bartram, C.I. (1994) Third degree obstetric anal sphincter tears: Risk factors and outcome of primary repair. British $\mathrm{Me}$ dical Journal, 308, 877-891. doi:10.1136/bmj.308.6933.887

[13] Kammerer-Doak, D.N., Wesol, A.B., Rogers, R.G., Dominguez, C.E. and Dorin, M.H. (1999) A prospective cohort study of women after primary repair of obstetric anal sphincter laceration. American Journal of Obstetrics \& Gynecology, 181, 1317-1322. doi:10.1016/S0002-9378(99)70370-4

[14] Williams, A., Adams, E.J., Tincello, D.G., Alfirevic, Z., Walkinshaw, S.A. and Richmond, D.H. (2006) How to repair an anal sphincter injury after vaginal delivery: Results of a randomised controlled trial. An International Journal of Obstetrics \& Gynaecology, 113, 201-107. doi:10.1111/j.1471-0528.2006.00806.x

[15] Fitzpatrick, M., Behan, M., O’Connell, P.R. and O’Herlihy, C. (2000) A randomized clinical trial comparing primary overlap with approximation repair of third-degree obstetric tears. American Journal of Obstetrics \& Gynecology, 183, 1220-1224. doi:10.1067/mob.2000.108880
[16] Homsi, R., Daikoku, N.H., Littlejohn, J. and Wheeless, C.R. (1994) Episiotomy: Risks of dehiscence and rectovaginal fistula. Obstetrical \& Gynecological Survey, 49, 803-808. doi:10.1097/00006254-199412000-00002

[17] Sultan, A.H., Monga, A.K., Kumar, D. and Stanton, S.L. (1999) Primary repair of obstetric anal sphincter rupture using the overlap technique. British Journal of Obstetrics and Gynaecology, 106, 318-323. doi:10.1111/j.1471-0528.1999.tb08268.x

[18] Rygh, A.B., et al. (2010) The overlap technique versus end-to-end approximation technique for primary repair of obstetric anal sphincter rupture: A randomized controlled study. Acta Obstetricia et Gynecologica Scandinavica, 89, 1256-1262. doi:10.3109/00016349.2010.512073

[19] Kalis, V., Bednarova, B., et al. (2010) Repair of the 3rd and 4th degree obstetric perineal tear. Ceská Gynekologie, 75, 284-291.

[20] Legino, L.J., Woods, M.P., Rayburn, W.F. and McGoogan, L.S. (1988) Third- and fourth-degree perineal tears-50 years' experience at a university hospital. The Journal of Reproductive Medicine, 33, 423-426.

[21] Abdul, H., et al. (1999) Primary repair of obstetric anal sphincter rupture using the overlap technique. British Journal of Obstetrics and Gynecology, 106, 318-323.

[22] Lisa, B. et al. (2000) Midline episiotomy and anal incontinence: Retrospective cohort study. British Medical Journal, 320, 86-90.

[23] Nordenstam, J. (2010) Anal Incontinence and Obstetric Anal Sphincter Tears. Karolinska Institutet, Stockholm.

[24] Fernando, R., Sultan, A.H., Kettle, C., Thakar, R. and Radley, S. (2006) Methods of repair for obstetric anal sphincter injury. Cochrane Database of Systematic Reviews, 19, CD002866.

[25] Poen, A.C., Felt-Bersma, R.J., Dekker, G.A., Deville, W. Cuesta, M.A. and Meuwissen, S.G. (1997) Third degree obstetric perineal tears: Risk factors and the preventative role of mediolateral episiotomy. An International Journal of Obstetrics \& Gynaecology, 104, 563-566. doi:10.1111/j.1471-0528.1997.tb11533.x

[26] Nordenstam, J.F., et al. (2010) Impaired rectal sensation at anal manometry is associated with anal incontinence one year after primary sphincter repair in primiparous women. Diseases of the Colon \& Rectum, 53, 1409-1414. doi:10.1007/DCR.0b013e3181eb9f01 